\title{
BMJ Open Technical efficiency and productivity of Chinese county hospitals: an exploratory study in Henan province, China
}

\author{
Zhaohui Cheng, Hongbing Tao, Miao Cai, Haifeng Lin, Xiaojun Lin, Qin Shu, \\ Ru-ning Zhang
}

To cite: Cheng Z, Tao $\mathrm{H}$, Cai M, et al. Technical efficiency and productivity of Chinese county hospitals: an exploratory study in Henan province, China. BMJ Open 2015:5:e007267.

doi:10.1136/bmjopen-2014007267

- Prepublication history for this paper is available online. To view these files please visit the journal online (http://dx.doi.org/10.1136/ bmjopen-2014-007267).

Received 21 November 2014 Revised 12 June 2015 Accepted 24 August 2015

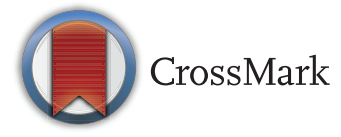

Department of Health Management, School of Medicine and Health Management, Tongji Medical College, Huazhong University of Science and Technology, Wuhan, Hubei province, People's Republic of China

Correspondence to Dr Hong-bing Tao; hhbtao@hust.edu.cn

\section{ABSTRACT}

Objectives: Chinese county hospitals have been excessively enlarging their scale during the healthcare reform since 2009. The purpose of this paper is to examine the technical efficiency and productivity of county hospitals during the reform process, and to determine whether, and how, efficiency is affected by various factors.

Setting and participants: 114 sample county hospitals were selected from Henan province, China, from 2010 to 2012.

Outcome measures: Data envelopment analysis was employed to estimate the technical and scale efficiency of sample hospitals. The Malmquist index was used to calculate productivity changes over time. Tobit regression was used to regress against 4 environmental factors and 5 institutional factors that affected the technical efficiency.

Results: (1) 112 (98.2\%), 112 (98.2\%) and 104 $(91.2 \%)$ of the 114 sample hospitals ran inefficiently in 2010, 2011 and 2012, with average technical efficiency of $0.697,0.748$ and 0.790 , respectively. (2) On average, during 2010-2012, productivity of sample county hospitals increased by $7.8 \%$, which was produced by the progress in technical efficiency changes and technological changes of $0.9 \%$ and $6.8 \%$, respectively. (3) Tobit regression analysis indicated that government subsidy, hospital size with above 618 beds and average length of stay assumed a negative sign with technical efficiency; bed occupancy rate, ratio of beds to nurses and ratio of nurses to physicians assumed a positive sign with technical efficiency.

Conclusions: There was considerable space for technical efficiency improvement in Henan county hospitals. During 2010-2012, sample hospitals experienced productivity progress; however, the adverse change in pure technical efficiency should be emphasised. Moreover, according to the Tobit results, policy interventions that strictly supervise hospital bed scale, shorten the average length of stay and coordinate the proportion among physicians, nurses and beds, would benefit hospital efficiency.

\section{Strengths and limitations of this study}

- This study not only evaluated the technical efficiency and productivity of county hospitals in Henan province, China, during the period of healthcare reform, but also explored factors impacting on technical efficiency, which have not been analysed before.

- The study provided an insight into the performance of county hospitals during the reform process in China, which can assist policymakers in choosing the best regulatory framework for the ongoing hospital reform process.

- This study was not able to collect information about case-mix index or patient outcome quality of each hospital due to the dated hospital information system.

- County hospitals in other regions of China were not included in this study.

\section{INTRODUCTION}

As China is the most populous country in the world, its healthcare system, potentially affecting the lives of 1.36 billion people, is of concern to researchers all over the world. The healthcare system in China consists of community health centres, and secondary and tertiary hospitals, in the urban areas, while rural areas have village clinics, township health centres and county hospitals. Hospitals are classified into three levels: tertiary, secondary and primary. Tertiary hospitals have more than 500 beds, treat complicated diseases and provide specialised care. Secondary hospitals have 100-499 beds and treat common illnesses, while primary hospitals have 20-99 beds, and provide preventive and basic medical services. ${ }^{1}$ Among the health service providers in the healthcare system, county hospitals play a crucial role. They serve as the leader of the three-tier 
healthcare network in rural areas, and connect patients in the village to urban tertiary hospitals. ${ }^{2}{ }^{3}$ In 2012, the number of county hospitals reached 10940 , accounting for $47.22 \%$ of the total number of hospitals, covering more than 900 million people, and providing medical services to approximately $70 \%$ of county residents. ${ }^{4}$ Their performance has a significant effect on the wellbeing of the Chinese people. In this paper, we examine county hospitals.

China has achieved an economic miracle since the economic reforms in 1978. However, the development of efficiency and equity in healthcare has for long lagged behind. ${ }^{5}$ Healthcare expenditure has been growing rapidly, but the proportion of the population with access to healthcare has diminished, widening health gaps between urban and rural areas. ${ }^{6-8}$ In response to these inequities, the government of China launched the Healthcare Reform Plan in 2009, and promised to build a safe, effective, convenient and inexpensive universal healthcare network. The plan has five key tasks: ${ }^{9}$ (1) expanding the coverage of health insurance; (2) establishing an essential drug distribution system; (3) strengthening primary care facilities; (4) promoting equitable access to public health services; and (5) piloting reform of public hospitals. Substantial positive results have been achieved from the reform. For instance, health insurance coverage has been expanded to cover more than $96 \%$ of residents; primary healthcare networks have been strengthened, in particular, 2200 county hospitals have been rebuilt or upgraded. ${ }^{10}$ Along with the expansion of health insurance coverage and the strengthening of county hospitals, people's health demands were quickly increasing. A number of county hospitals have increased their beds scale to meet the rising demands. During 2009-2013, the number of beds in county hospitals expanded from 765510 to 1238500 , and the total number of inpatients increased from 26228716 to 44565675 . ${ }^{11}$ Technical efficiency (TE) of county hospitals, trend of productivity and factors affecting efficiency are all important considerations under these conditions.

There has been an extensive body of literature dealing with the efficiency of healthcare, and data envelopment analysis (DEA) is the best known methodology and is widely used. Hollingsworth $e t a l^{12}$ systematically reviewed DEA articles on healthcare, involving a wide range of applications. Barnum et $a l^{13}$ employed DEA to measure the efficiency of hospital pharmacies in America. Dimas et $a l^{14}$ evaluated the productivity of 22 Greek public hospitals, and found that productivity changes were dominated by technical change. Zere et $a l^{15}$ measured the TE and productivity of 86 hospitals in South Africa, and examined the impact of hospital characteristics on efficiency and productivity, using Tobit and Ordinary Least Square (OLS) regression. Tlotlego et $a l^{16}$ adopted the Malmquist index to analyse the productivity of 21 nonteaching hospitals in Botswana during 2006-2008, and found significant inefficiencies. In China, $\mathrm{Ng}^{17}$ evaluated the productivity of hospitals in Guangdong province, and found that productivity growth was deteriorating as technology progress. Li et $a l^{18}$ researched the productivity of 12 tertiary hospitals in Beijing during 2006-2009, and found that sample hospitals were experiencing productivity growth with technological changes (TCs).

In this paper, we focused on the performance of county hospitals in Henan province, China. Henan, with 105.43 million people, is the most populous province in China, and $57.6 \%$ of this population live in rural areas. The total health expenditure in Henan province was US $\$ 23.3$ billion, accounting for $5.13 \%$ of its gross domestic product (GDP) ${ }^{19}$ County hospitals play a crucial role in Henan's healthcare system. During 2010-2012, county hospitals developed significantly: the number of beds in county hospitals increased by $11.34 \%$, reaching 78696 , and accounting for $62.81 \%$ of the total number of secondary hospitals. ${ }^{20}$ In addition, more than $15.64 \%$ of the total expenditure on health was spent in county hospitals. ${ }^{19}$ Though much has changed in Henan county hospitals, little is known about their performance. Thus, the overall objectives of this paper were: (1) to measure the TE of Henan county hospitals during the reform process from 2010 to 2012; (2) to evaluate changes in productivity during the reform; (3) to determine whether, and how, TE is affected by various factors.

\section{METHODS}

\section{Efficiency evaluation methods}

To measure the efficiency of healthcare organisations, two frontier methodologies, stochastic frontier analysis (SFA) and DEA, have been widely applied. ${ }^{21-24}$ In comparison with DEA, SFA requires constructing an efficient frontier function, and the information of input prices, output prices and total costs is difficult to acquire. ${ }^{25} 26$ Thus, considering the convenience and the multiple inputs and outputs, we applied DEA in this paper.

\section{Data envelopment analysis}

Charnes, Cooper and Rhodes (CCR), Banker, Charnes, Cooper (BCC) and Malmquist productivity index, as models of DEA, have been widely used to measure relative efficiency and productivity. The CCR model, which was proposed by Charnes et al, ${ }^{27}$ assumes that production is constant return to scale (CRS), which means an increase in the input(s) will result in a proportionate increase in the output(s). When a hospital is operating at CRS, TE is equal to scale efficiency (SE). However, when Decision Making Units (DMUs) are not operating at optimum scale, TE measured with the CCR model may be altered by SE. The BCC model, which was proposed by Banker et $a l,{ }^{28}$ assumes that production is variable return to scale (VRS), which means an increase in the input(s) will result in either an increase or a decrease in the output(s). VRS has two dimensions: increasing returns to scale (IRS), which means $1 \%$ increase in inputs will be followed by more than $1 \%$ 
increase in outputs, and decreasing returns to scale (DRS), which means $1 \%$ increase in inputs will result in less than $1 \%$ increase in outputs. The BCC model can incorporate the impact of SE in measurement of TE. ${ }^{29}$

$$
\mathrm{SE}=\frac{\mathrm{TE}_{\mathrm{CRS}}}{\mathrm{TE}_{\mathrm{VRS}}}
$$

The Malmquist productivity index, developed by Färe et $a l^{30}$ can take into account the productivity changes of hospitals in a time-series setting. Total factor productivity change (TFPC) can be decomposed into TE changes (TECs) and TCs. In the Malmquist productivity index, five indices can be generated: TFPC, TEC, TC, pure TEC (PTEC) and SE change (SEC). ${ }^{18} 31$

$$
\mathrm{TFPC}=\mathrm{TEC} \times \mathrm{TC}=(\mathrm{PTEC} \times \mathrm{SEC}) \times \mathrm{TC}
$$

\section{Input orientation}

In this paper, an input-oriented DEA was employed for the following reasons. First, due to the ineffectiveness of the tiered Chinese diagnosis and treatment system, the selection of hospitals depends on patients, which makes it difficult for hospitals to estimate the actual healthcare demand. Second, the input orientation reflects the regulated context of Chinese county hospitals, that hospital managers have more control over their inputs (staffing and operating expenses or beds) than they do over outputs (patients get admitted or visit the outpatient department). Third, the input orientation is more consistent with the functional orientation of county hospitals in China, which is obliged to meet people's basic and commonest health demands with reducing or limiting input use. In addition, the selection of input orientation is also conformed to the character of the non-profit organisation, which focuses on the minimisation of inputs with given outputs, and the selection is consistent with other empirical research regarding hospital efficiency evaluation. ${ }^{172332}$

\section{Tobit regression analysis}

In this paper, the Tobit regression model was employed to relate the $\mathrm{TE}_{\mathrm{CRS}}$ to a number of explanatory variables. Considering that the efficiency scores fall between 0 and 1 , and several scores tend to concentrate on these boundary values (ie, censored at 1), ordinary least squares are inapplicable. ${ }^{33}$ Therefore, the Tobit model was applied..$^{34}$ For convenient computation, in the Tobit model, a censoring point is preferable to assume at zero, so that fully efficient hospitals could be constrained at 0 whereas the inefficient hospitals showed scores greater than 0. Following Asbu, ${ }^{35}$ the $\mathrm{TE}_{\mathrm{CRS}}$ scores were transformed into inefficiency scores and left censored at 0 using the formula:

$$
\text { Inefficiency score }=\left(\frac{1}{\mathrm{TE}_{\mathrm{CRS}}}\right)-1
$$

This transformation of the dependent variable also reversed the signs of the coefficient in the regression.

\section{DATA}

The sample county hospitals in this study were selected from Henan province, China. Data were obtained from the National Health Statistical Information Report System during 2010-2012. Since the basic requirement in applying DEA is to select a group of similar units, the samples were carefully scrutinised to eliminate errors. First, to reduce differences in disease complexity, and in medical technology and quality of care among hospitals, only public county general hospitals were selected. Second, hospitals with the data of default values or abnormal values were excluded. Third, hospitals without data for three consecutive years were excluded to ensure consistency. Finally, 114 public county general hospitals in Henan province were selected in the data set.

\section{VARIABLES SELECTION}

\section{Input and output variables}

In this paper, the selection of input and output variables were guided by previous empirical studies, ${ }^{17} 18$ 36-38 and depended on the availability of data in the National Health Statistical Information Report System.

Regarding the input variables, both labour and capital were considered important in delivering health services. In this paper, the labour variables focused on two indicators: 'the number of physicians' and 'the number of nurses'. Regarding capital, most studies considered 'the number of beds' as a proxy of capital inputs. Owing to the dynamic situation of hospitalisation in China, characterised by the use of many temporary beds, 'actual number of open beds' instead of 'the number of beds', was considered.

Regarding the output variables, following the hospital efficiency studies conducted by Tlotlego et $a l^{16}$ and Li et $a l^{18}$ hospital outputs in this study were represented by 'the number of outpatient and emergency visits' and 'the number of inpatient days'. Since inpatient health services have different features and consume more resources than outpatient services, the use of 'inpatient days' was more medically homogeneous than the 'inpatient' variable and can provide a more favourable hospital output.

The output variables in this study are all aggregated; however, hospitals provide services to patients who differ in terms of case-mix variation and quality. Since there was no available data to accurately measure the case-mix indices based on diagnosis-related groups, the use of case-mixed index was limited for hospitals in China as well as in other developing countries. ${ }^{39}$

The descriptive analysis of the inputs and outputs was conducted using SPSS V.13.0 statistical software. TE and productivity were computed using DEAP V.2.1 software. ${ }^{40}$ 


\section{Explanatory variables}

In the Tobit regression analysis, the technical inefficiency scores were regressed against a set of environmental characteristics and several institutional factors.

Following literature review, factors that influence hospital efficiency were classified. Environmental factors include: GDP/GDP per capita, catchment population, geographic location, market structure/competition and government subsidy. Institutional factors include: ownership, hospital size/capacity, output quality, teaching status, bed occupancy rate (OCCU), average length of stay (ALoS), ratio of nurses to physicians (RONTP) and ratio of beds to nurses (ROBTN) $.^{21} 3841-43$ Considering the samples in this study were public county general hospitals from Henan and relevant data regarding quality was unavailable, the environmental factor of location and institutional factors of ownership, output quality and teaching status, were excluded.

Thus, four environmental variables including 'catchment population', 'GDP per capita', 'HerfindahlHirschman Index (HHI)' and 'government subsidy', as well as five institutional variables including 'hospital beds group', 'ALoS', 'OCCU', 'RONTP' and 'ROBTN', were selected for inclusion in this study. The estimated Tobit model was as follows:

$$
\begin{aligned}
\text { Ineff }= & \beta_{0}+\beta_{1} \text { POP }+\beta_{2} \text { GDP per capita }+\beta_{3} \text { HHI } \\
& +\beta_{4} \text { GOV subsidy }+\beta_{5} \text { BED group }+\beta_{6} \text { ALoS } \\
& +\beta_{7} \text { OCCU }+\beta_{8} \text { RONTP }+\beta_{9} \text { ROBTN }+\varepsilon_{i}
\end{aligned}
$$

Where Ineff is the technical inefficiency score, POP is the region catchment population dummy variable $(0=$ if population is less than $500000 ; 1=$ if population is 500000 and above); HHI is a variable that describes market competition; BED group is the hospital beds dummy variable, beds were stratified according to quartiles (size $1=$ hospitals with $100-227$ beds; size $2=$ hospitals with 228-445 beds; size 3=hospitals with 446-617 beds; size $4=$ hospitals with more than 618 beds); and $\varepsilon_{\mathrm{i}}$ is the error term. Tobit regression was conducted using STATA V.11.0 statistical software. ${ }^{44}$

\section{RESULTS}

The descriptive statistics of inputs, outputs and explanatory variables are shown in table 1 .

The TE and SE of sample county hospitals during 2010-2012 are shown in table 2.

\section{Overall TE ( $\left.\mathrm{TE}_{\mathrm{CRS}}\right)$}

For the years 2010, 2011 and 2012, out of the 114 hospitals, $2(1.8 \%), 2(1.8 \%)$ and $10(8.8 \%)$ hospitals, respectively, were defined as technically efficient. While, 112 (98.2\%), $112(98.2 \%)$ and $104(91.2 \%)$ hospitals were inefficient, respectively. Average $\mathrm{TE}_{\mathrm{CRS}}$ was 0.697 , 0.748 and 0.790 , respectively.
Pure TE (TE $\left.\mathrm{VRS}_{\mathrm{V}}\right)$

In 2010, 2011 and 2012, $6(5.3 \%), 9(7.9 \%)$ and 18 $(15.8 \%)$ hospitals, respectively, operated at the best efficiency levels, with a $\mathrm{TE}_{\mathrm{VRS}}$ score of 1.000. In total, 108 $(94.7 \%), 105(92.1 \%)$ and $96(84.2 \%)$ hospitals, respectively, operated inefficiently. Average $\mathrm{TE}_{\mathrm{VRS}}$ was 0.751 , 0.789 and 0.816 , respectively, implying that if they run efficiently, the hospitals should decrease $24.9 \%, 21.1 \%$ and $18.4 \%$ of inputs for the same volume of outputs.

\section{Scale efficiency}

As shown in table 2, for the years 2010, 2011 and 2012, average SE was $0.932,0.949$ and 0.969 , respectively.

Six $(5.3 \%), 11(9.7 \%)$ and $19(16.7 \%)$ hospitals manifested CRS, indicating that they operated at their most productive size. One hundred $(87.7 \%), 96(84.2 \%)$ and $83(72.8 \%)$ showed IRS, suggesting that they should expand their scale to become scale efficient. Eight $(7.0 \%), 7(6.1 \%)$ and $12(10.5 \%)$ hospitals experienced DRS, meaning that they should scale down to become scale efficient. Average number of beds in IRS, CRS and DRS hospitals, respectively, was 366, 537 and 701 . Hospitals of DRS had more beds than those of IRS and CRS (Mann-Whitney $\mathrm{U}$ test $\mathrm{Z}=-3.065$, $\mathrm{p}=0.002$; MannWhitney $\mathrm{U}$ test $\mathrm{Z}=-6.692, \mathrm{p}=0.000)$.

\section{Potential input reductions}

In order to make inefficient county hospitals operate efficiently, there would be potential for significant input savings. Table 3 presented the total inputs that needed reductions. In 2012, for example, the inefficient hospitals combined would need to reduce the number of physicians, nurses and beds by 3417 (24.54\%), 5029 (22.70\%) and $10233(19.44 \%)$, respectively.

\section{Productivity growth (TFPC)}

The Malmquist productivity index was applied to analyse the changes in productivity over the 2010-2012 period, and the year 2010 has been taken as the technology reference. Table 4 presents the Malmquist index summary of annual geometric means. On average, TFPC increased by $7.8 \%$, among which, TC increased by $6.8 \%$ and TEC increased slightly by $0.9 \%$. Thus, the increase of TC was the main contributor for the TFPC improvement. During 2010-2012, 88 (77.2\%) hospitals had TFPC scores greater than 1, indicating growth in productivity; 26 (22.8\%) hospitals had TFPC scores less than 1 , indicating deterioration in productivity.

\section{Technological change}

During 2010-2012, all sample hospitals experienced technical progress. The average TC score was 1.068 , indicating a $6.8 \%$ technical improvement over the period.

\section{TE changes}

TEC is a product of PTEC and SEC. During 2010-2012, the average TEC was 1.009 , for an improvement in SEC of $1.9 \%$, and counterbalanced by the decline in PTEC 
Table 1 Descriptive statistics of inputs, outputs and explanatory variables

\begin{tabular}{|c|c|c|c|c|c|c|c|}
\hline & 2010 & 2011 & 2012 & & 2010 & 2011 & 2012 \\
\hline \multicolumn{4}{|l|}{ Inputs } & \multicolumn{4}{|l|}{ Outputs } \\
\hline \multicolumn{4}{|l|}{ Physicians } & \multicolumn{4}{|c|}{ Outpatient and emergency visits } \\
\hline Mean & 112 & 114 & 122 & Mean & 170008 & 190256 & 218887 \\
\hline Maximum & 256 & 237 & 344 & Maximum & 498574 & 583348 & 593502 \\
\hline Minimum & 23 & 20 & 20 & Minimum & 26280 & 28291 & 34920 \\
\hline SD & 51 & 55 & 62 & SD & 94413 & 103403 & 115943 \\
\hline \multicolumn{4}{|l|}{ Nurses } & \multicolumn{4}{|c|}{ Inpatient Days } \\
\hline Mean & 153 & 174 & 194 & Mean & 112391 & 127401 & 152491 \\
\hline Maximum & 430 & 453 & 575 & Maximum & 298062 & 342384 & 390013 \\
\hline Minimum & 27 & 26 & 23 & Minimum & 15862 & 23250 & 23253 \\
\hline SD & 80 & 95 & 110 & SD & 64341 & 74159 & 88382 \\
\hline \multicolumn{8}{|l|}{ Hospital beds } \\
\hline Mean & 373 & 396 & 462 & & & & \\
\hline Maximum & 915 & 1109 & 1109 & & & & \\
\hline Minimum & 100 & 100 & 100 & & & & \\
\hline SD & 193 & 213 & 243 & & & & \\
\hline \multicolumn{8}{|c|}{ Explanatory variables } \\
\hline \multicolumn{4}{|c|}{ GDP per capita } & \multicolumn{4}{|l|}{ ALoS } \\
\hline Mean & 24957 & 29084 & 31236 & Mean & 7.8 & 7.9 & 7.9 \\
\hline Maximum & 70006 & 70473 & 74571 & Maximum & 14.5 & 14.6 & 14.6 \\
\hline Minimum & 9282 & 11531 & 13975 & Minimum & 4.7 & 5.0 & 4.1 \\
\hline SD & 13249 & 1486 & 15808 & SD & 1.6 & 1.6 & 1.6 \\
\hline \multicolumn{4}{|c|}{ Catchment population (POP) } & \multicolumn{4}{|l|}{ OCCU } \\
\hline Mean & 660000 & 650000 & 650000 & Mean & $85.0 \%$ & $90.4 \%$ & $92.5 \%$ \\
\hline Maximum & 160000 & 1630000 & 1630000 & Maximum & $115.6 \%$ & $131.2 \%$ & $149.0 \%$ \\
\hline Minimum & 70000 & 70000 & 70000 & Minimum & $33.2 \%$ & $42.2 \%$ & $43.1 \%$ \\
\hline SD & 270000 & 270000 & 260000 & SD & $16.2 \%$ & $14.9 \%$ & $14.8 \%$ \\
\hline \multicolumn{4}{|l|}{$\mathrm{HHI}$} & \multicolumn{4}{|l|}{ RONTP } \\
\hline Mean & 504 & 519 & 524 & Mean & 1.37 & 1.56 & 1.63 \\
\hline Max & 1278 & 1287 & 1310 & Max & 2.27 & 3.90 & 4.30 \\
\hline Min & 288 & 286 & 285 & Min & 0.57 & 0.50 & 0.46 \\
\hline SD & 168 & 170 & 172 & SD & 0.36 & 0.52 & 0.60 \\
\hline \multicolumn{4}{|c|}{$\begin{array}{l}\text { Proportion of government subsidy in hospital revenues } \\
\text { (GOV subsidy) }\end{array}$} & ROBTN & & & \\
\hline Mean & $4.59 \%$ & & $5.84 \%$ & Mean & 2.60 & 2.48 & 2.69 \\
\hline Maximum & $50.11 \%$ & 43.5 & $78.92 \%$ & Maximum & 5.56 & 6.84 & 8.87 \\
\hline Minimum & $0.00 \%$ & & $0.00 \%$ & Minimum & 1.21 & 1.29 & 1.02 \\
\hline SD & $7.65 \%$ & 7.7 & $10.18 \%$ & SD & 0.84 & 0.93 & 1.29 \\
\hline
\end{tabular}

ALoS, average length of stay; GDP, gross domestic product; HHI, Herfindahl-Hirschman Index; OCCU, bed occupancy rate; POP, regional catchment population dummy variable; ROBTN, ratio of beds to nurses; RONTP, ratio of nurses to physicians.

of $1 \%$. In this study, the average PTEC was 0.990 less than the average SEC of 1.019 , meaning that there was an inefficient use of inputs. During 2010-2011 and 2011-2012, average SEC decreased from 1.049 to 0.990 , and average PTEC increased from 0.981 to 1.000 .

\section{Tobit regression analysis of impacting factors on technical} inefficiency

In this paper, Tobit regression was employed to relate the technical inefficiency scores to four environmental and five institutional variables in 2012, the last year. The results are presented in table 5 .

Regarding environmental factors, 'POP' $(\mathrm{p}=0.382)$, 'GDP per capita' $(p=0.121)$ and 'HHI' $(p=0.482)$ were, respectively, statistically insignificant. However, 'GOV subsidy' exhibited a positive and significant sign
( $\mathrm{p}=0.062)$, indicating that sample hospitals with a higher proportion of government subsidy were possibly technically inefficient.

Regarding institutional factors, 'BED group of SIZE 4' was positively associated with technical inefficiency $(p=0.000)$, indicating that sample hospitals with more than 618 beds have lower TE. The 'ALoS' was statistically significant $(p=0.021)$ and assumed a positive sign with technical inefficiency. Internal management variables, such as 'OCCU', 'RONTP' and 'ROBTN', assumed negative signs with technical inefficiency and were statistically significant $(\mathrm{p}<0.001)$.

\section{DISCUSSION}

The results of this study indicated that sample county hospitals experienced significant technical inefficient 
Table 2 Technical and scale efficiency of hospitals, and frequency distribution during 2010-2012

\begin{tabular}{|c|c|c|c|c|c|c|c|c|c|}
\hline & \multicolumn{3}{|l|}{2010} & \multicolumn{3}{|l|}{2011} & \multicolumn{3}{|l|}{2012} \\
\hline & $\mathrm{TE}_{\mathrm{CRS}}$ & TE $_{\text {VRS }}$ & SE & $\mathrm{TE}_{\mathrm{CRS}}$ & $T_{\text {VRS }}$ & SE & $\mathrm{TE}_{\mathrm{CRS}}$ & TE $_{\text {VRS }}$ & SE \\
\hline Mean & 0.697 & 0.751 & 0.932 & 0.748 & 0.789 & 0.949 & 0.790 & 0.816 & 0.969 \\
\hline Median & 0.722 & 0.741 & 0.984 & 0.749 & 0.777 & 0.990 & 0.788 & 0.812 & 0.992 \\
\hline Maximum & 1.000 & 1.000 & 1.000 & 1.000 & 1.000 & 1.000 & 1.000 & 1.000 & 1.000 \\
\hline Minimum & 0.297 & 0.492 & 0.441 & 0.353 & 0.564 & 0.536 & 0.482 & 0.518 & 0.721 \\
\hline SD & 0.129 & 0.112 & 0.122 & 0.123 & 0.112 & 0.091 & 0.121 & 0.119 & 0.056 \\
\hline \multicolumn{10}{|c|}{ Hospital ranking } \\
\hline $100 \%$ & $2(1.8 \%)$ & $6(5.3 \%)$ & $6(5.3 \%)$ & $2(1.8 \%)$ & $9(7.9 \%)$ & $9(7.9 \%)$ & $10(8.8 \%)$ & $18(15.8 \%)$ & $17(14.9 \%)$ \\
\hline 80-99.9\% & $22(19.3 \%)$ & $31(27.2 \%)$ & $94(82.4 \%)$ & $39(34.2 \%)$ & $40(35.1 \%)$ & $97(85.1 \%)$ & $46(40.3 \%)$ & 46 (40.4\%) & 92 (80.7\%) \\
\hline 60-79.9\% & $63(55.3 \%)$ & 68 (59.6\%) & $14(12.3 \%)$ & $61(53.5 \%)$ & 62 (54.4\%) & $8(7.0 \%)$ & $53(46.5 \%)$ & $47(41.2 \%)$ & $5(4.4 \%)$ \\
\hline $40-59.9 \%$ & $24(21.0 \%)$ & $9(7.9 \%)$ & $0(0.0 \%)$ & $10(8.8 \%)$ & $3(2.6 \%)$ & $0(0.0 \%)$ & $5(4.4 \%)$ & $3(2.6 \%)$ & $0(0.0 \%)$ \\
\hline$<40 \%$ & $3(2.6 \%)$ & $0(0.0 \%)$ & $0(0.0 \%)$ & $2(1.7 \%)$ & $0(0.0 \%)$ & $0(0.0 \%)$ & $0(0.0 \%)$ & $0(0.0 \%)$ & $0(0.0 \%)$ \\
\hline
\end{tabular}

Table 3 Total input reductions needed to make hospitals efficient

\begin{tabular}{|c|c|c|c|c|c|c|c|c|c|}
\hline \multirow[b]{2}{*}{ Inputs } & \multicolumn{3}{|l|}{2010} & \multicolumn{3}{|l|}{2011} & \multicolumn{3}{|l|}{2012} \\
\hline & $\begin{array}{l}\text { Actual } \\
\text { values }\end{array}$ & $\begin{array}{l}\text { Target } \\
\text { values }\end{array}$ & Difference (\%) & $\begin{array}{l}\text { Actual } \\
\text { values }\end{array}$ & $\begin{array}{c}\text { Target } \\
\text { values }\end{array}$ & Difference (\%) & $\begin{array}{l}\text { Actual } \\
\text { values }\end{array}$ & $\begin{array}{l}\text { Target } \\
\text { values }\end{array}$ & Difference (\%) \\
\hline Physicians & 12806 & 8769 & $-4037(-31.53 \%)$ & 13006 & 9527 & $-3479(-26.75 \%)$ & 13925 & 10508 & $-3417(-24.54 \%)$ \\
\hline Nurses & 17494 & 12717 & $-4777(-27.31 \%)$ & 19849 & 15003 & $-4846(-24.42 \%)$ & 22153 & 17124 & $-5029(-22.70 \%)$ \\
\hline Beds & 42476 & 31536 & $-10940(-25.75 \%)$ & 45146 & 35100 & $-10046(-22.25 \%)$ & 52627 & 42394 & $-10233(-19.44 \%)$ \\
\hline
\end{tabular}


Table 4 Malmquist index summary of annual means (input oriented)

\begin{tabular}{|c|c|c|c|c|c|}
\hline Year & $\begin{array}{l}\text { Technical efficiency } \\
\text { change }(A=(C \times D))\end{array}$ & $\begin{array}{l}\text { Technological } \\
\text { change (B) }\end{array}$ & $\begin{array}{l}\text { Pure technical efficiency } \\
\text { change }(C)\end{array}$ & $\begin{array}{l}\text { Scale efficiency } \\
\text { change }(D=(A / C))\end{array}$ & $\begin{array}{l}\text { Total factor productivity } \\
\text { change }(E=A \times B)\end{array}$ \\
\hline 2011 & 1.029 & 1.058 & 0.981 & 1.049 & 1.088 \\
\hline 2012 & 0.989 & 1.079 & 1.000 & 0.990 & 1.067 \\
\hline Mean & 1.009 & 1.068 & 0.990 & 1.019 & 1.078 \\
\hline \multicolumn{6}{|c|}{ Frequency distribution (2010-2012) } \\
\hline$>1$ & $56(49.1 \%)$ & $114(100.0 \%)$ & $43(37.7 \%)$ & $66(57.9 \%)$ & $88(77.2 \%)$ \\
\hline 1 & $2(1.8 \%)$ & $0(0.0 \%)$ & $13(11.4 \%)$ & $6(5.3 \%)$ & $0(0.0 \%)$ \\
\hline$<1$ & $56(49.1 \%)$ & $0(0.0 \%)$ & $58(50.9 \%)$ & $42(36.8 \%)$ & $26(22.8 \%)$ \\
\hline \multicolumn{6}{|c|}{ Frequency distribution (2010-2011) } \\
\hline$>1$ & $59(51.8 \%)$ & $112(98.2 \%)$ & $39(34.2 \%)$ & $90(78.9 \%)$ & $85(74.6 \%)$ \\
\hline 1 & $5(4.4 \%)$ & $0(0.0 \%)$ & $17(14.9 \%)$ & $7(6.1 \%)$ & $0(0.0 \%)$ \\
\hline$<1$ & $50(43.8 \%)$ & $2(1.8 \%)$ & $58(50.9 \%)$ & $17(15.0 \%)$ & $29(25.4 \%)$ \\
\hline \multicolumn{6}{|c|}{ Frequency distribution (2011-2012) } \\
\hline$>1$ & $50(43.8 \%)$ & $114(100.0 \%)$ & $50(43.8 \%)$ & $30(26.3 \%)$ & $81(71.1 \%)$ \\
\hline 1 & $5(4.4 \%)$ & $0(0.0 \%)$ & $16(14.0 \%)$ & $7(6.1 \%)$ & $0(0.0 \%)$ \\
\hline$<1$ & $59(51.8 \%)$ & $0(0.0 \%)$ & $48(42.2 \%)$ & $77(67.6 \%)$ & $33(28.9 \%)$ \\
\hline
\end{tabular}

during 2010-2012. Only $1.8 \%, 1.8 \%$ and $8.8 \%$ of sample hospitals were defined as overall technically efficient, indicating a great need for efficiency improvement, while the average SE in sample hospitals was quite high and increased from 0.932 in 2010 to 0.969 in 2012. Thus, the lower level of pure TE, which progressed slightly from 0.751 to 0.816 over the period, may account for the overall technical inefficiency, while the efficiency of Henan county hospitals was lower than those reported in other provinces of China. For example, the average score of TE, pure TE and SE in county hospitals in Jiangxi was $0.936,0.978$ and 0.960 , respectively; ${ }^{45}$ and in Chongqing, during 2008-2011, it was $0.936,0.978$ and 0.960 , respectively. ${ }^{46}$ These

Table 5 Result from Tobit regression analysis $(\mathrm{N}=114$, year=2012)

\begin{tabular}{|c|c|c|c|c|}
\hline Variable & Coefficient & SE & t-Ratio & $p>|t|$ \\
\hline POP & -0.028 & 0.032 & -0.88 & 0.382 \\
\hline GDP per capita & -0.000 & 0.000 & -1.56 & 0.121 \\
\hline $\mathrm{HHI}$ & 0.000 & 0.000 & 0.70 & 0.482 \\
\hline GOV subsidy & 0.246 & 0.131 & 1.89 & $0.062^{*}$ \\
\hline \multicolumn{5}{|l|}{ Bed group } \\
\hline Size 2 (228-445) & 0.052 & 0.040 & 1.29 & 0.201 \\
\hline Size 3 (446-617) & 0.025 & 0.037 & 0.67 & 0.507 \\
\hline Size 4 (>618) & 0.112 & 0.037 & 3.00 & $0.003^{\star \star *}$ \\
\hline ALoS & 0.021 & 0.009 & 2.34 & $0.021^{\star *}$ \\
\hline OCCU & -1.294 & 0.100 & -12.92 & $0.000^{* * *}$ \\
\hline RONTP & -0.109 & 0.028 & -3.76 & $0.000^{\star \star \star}$ \\
\hline ROBTN & -0.103 & 0.013 & -8.05 & $0.000^{* * *}$ \\
\hline Constant & 1.713 & 0.137 & 12.52 & $0.000^{* * *}$ \\
\hline Sigma & 0.131 & 0.009 & & \\
\hline \multirow[t]{3}{*}{ Observations summary } & \multicolumn{4}{|c|}{10 left-censored observations at Ineff $\leq 0$} \\
\hline & \multicolumn{4}{|c|}{104 uncensored observations } \\
\hline & \multicolumn{4}{|c|}{0 right-censored observations at $I n e f f \geq 1$} \\
\hline Number of observations & \multicolumn{4}{|c|}{114 sample county hospitals in 2012} \\
\hline Log likelihood & \multicolumn{4}{|c|}{55.55} \\
\hline$\chi^{2}$ & \multicolumn{4}{|l|}{126.34} \\
\hline Probability $>\chi^{2}$ & \multicolumn{4}{|l|}{$0.00^{\star * *}$} \\
\hline \multicolumn{5}{|c|}{ 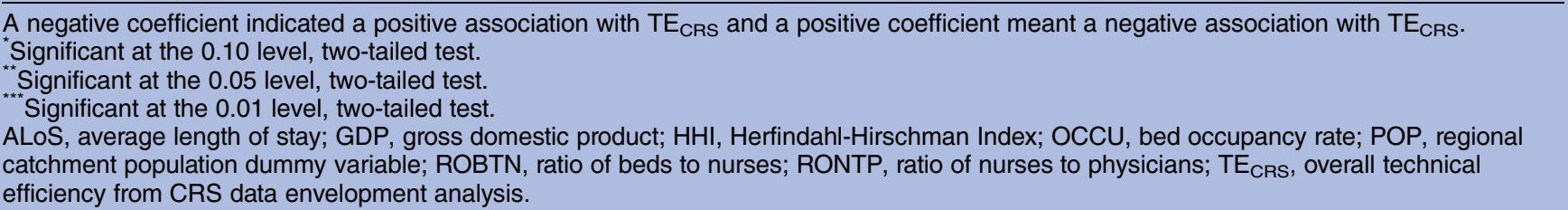 } \\
\hline
\end{tabular}


differences might be attributed to the differences among input-output indicators and external environments. In this paper, we also computed the potential for inputs savings. For example, the excess physicians, nurses and beds from inefficient hospitals, respectively, were 3417, 5029 and 10233 in 2012. Considering the substantial support from the Chinese government for encouraging the development of private hospitals, ${ }^{47} 48$ and the understaffed primary health facilities, ${ }^{8}$ policymakers might consider reassigning the excess hospital staff and beds to the private hospitals and primary health facilities where they are actually needed.

The results indicated that sample county hospitals were experiencing a TFPC progress during 2010-2012 and substantial TCs were the largest contributors, which was consistent with the findings in Shandong ${ }^{49}$ and Guangdong provinces. ${ }^{17}$ The average TFPC score of 1.078 in Henan county hospitals was also comparable to the scores in other countries, for instance, a score of 0.92 in Montreal, Canada, ${ }^{50} 1.028$ in regional hospitals in Ireland,$^{51} 1.045$ in Angolan municipal hospitals ${ }^{52}$ and of 1.209 in Brazilian federal university hospitals. ${ }^{53}$ There were many factors contributing to the TCs, while the adoption of high tech treatments and equipment contributed most in sample hospitals. $\mathrm{Ng}^{17}$ indicated the observed productivity growth from $68 \%$ to $94 \%$ resulted from the adoption of high tech treatments. In China, although the majority of hospitals are publicly owned, government subsidies account for less than $10 \%$ of their total revenues; the remaining $90 \%$ have to be obtained from revenue-generating activities. In addition, since health services in China have long been underpriced, hospitals have to obtain higher margins from services provided by high tech treatments or high tech equipment, which is a driving factor to increase their number of high tech treatments and equipment. As shown in our results, the TCs had increased each year. Pang and Wang $^{54}$ pointed out that the introduction of new medical devices and the use of new drugs, etc, can promote technological progress in the short term in Chinese hospitals. However, the lack of qualified staff and the inadequate use of medical equipment may reduce the technological efficiency in the long run, a fact that should be given more attention.

TEC insignificantly contributed to growth of the TFPC in the results, which was consistent with the findings of Li $e t a l^{18}$ The small progress or decline in TEC mainly results from the stagnation and decline of PTEC, which might be attributed to poor hospital governance and management. Despite having an autonomic authority in the generation and management of finances, county hospitals in China are governed by multiple bodies. Strategic hospital decisions are controlled by administrative rules and at least eight government ministries involved in appointment and management of personnel, internal organisation and investment decisions, etc. ${ }^{55}$ Moreover, hospital directors in China are mostly appointed by the local government, without well- designed mechanisms, rules and regulations; thus, the lack of clearly defined rights and responsibility increases their subjectivity in decision-making, which would decrease the quality of management practices and further influence pure TE. ${ }^{18}$ Fang et at ${ }^{4}$ summarised the problems among Chinese county hospitals, and put forward the 'corporate governance model' to improve hospital governance and management, which may help to improve pure TE in county hospitals. We also noticed that the SEC deteriorated during 2011-2012 after an increase in 2010-2011, which suggests that sample county hospitals should explore their optimum operation scale.

In this study, the Tobit regression results indicated that sample hospitals with a higher proportion of government subsidy in their revenues were assumed to be less efficient. The possible explanation is that, with the increase of government financial support, hospital directors were encouraged to expand bed size and purchase new equipment regardless of actual need, which may have led to lower utilisation and higher idle cost, and therefore reduced TE. The results showed that sample hospitals with between $228-445$ and $446-617$ beds, were statistically insignificant regarding $\mathrm{TE}_{\mathrm{CRS}}$, respectively. However, when hospital beds were over 618 , the $\mathrm{TE}_{\mathrm{CRS}}$ declined. Tan et $a \bar{P}^{6}$ explored the optimal scale of secondary hospitals in Beijing, and found that the strict and flexible control standard was 242-353 and 271-571 beds, respectively. Dong et $a \tilde{l}^{7}$ analysed the optimal scale of county hospitals in Hubei province, and found that the standard was $250-300$ beds. Vitaliano ${ }^{58}$ researched the hospitals' scale economy and indicated that it appears as a shallow U-shaped average cost curve: when hospital beds were beyond an optimum scale, the average cost increased. However, Chinese county hospitals have been experiencing an expansion in bed capacity in recent years, and the average number of beds in sample county hospitals has increased from 373 in 2010 to 462 in 2012. Therefore, directors of hospitals should attach great importance to the expansion of beds and keep hospital beds in an appropriate scale to improve or maintain efficiency. Inefficient hospitals because of large size and those hospitals experiencing DRS should reduce their bed scale.

The ALoS had a negative impact on TE of sample hospitals. The average ALoS was 7.9, which was longer than ALoSs in other countries. For example, in USA, the average ALoS was 5.0. ${ }^{59}$ Therefore, sample hospital managers should adopt necessary measures to reduce ALoS, for instance, implementing clinical pathway management, setting up the monitoring targets, innovating medical technology and spreading the application of ambulatory surgery, etc. The 'OCCU' showed a positive impact on TE in this study. In order to improve bed utilisation, the ALoS needs to be shortened to improve bed rotation rate. Moreover, the optimisation of service process is also required. In this study, 'RONTP' assumed a positive sign on $\mathrm{TE}_{\mathrm{CRS}}$. The 'ROBTN' also assumed a 
positive correlation with $\mathrm{TE}_{\mathrm{CRS}}$, and the average ratio was 2.59. In western countries, it was approximately 0.33. ${ }^{60}$ These gaps between Henan and those abroad may be attributed to the imbalanced allocation of staff and beds, which was mainly caused by the excessive expansion of beds in Henan county hospitals. ${ }^{55}$ In the short term, hospitals may operate with lower human cost (ie, higher RONTP and higher ROBTN) to get higher efficiency, as the Tobit results indicated. However, the imbalanced allocation at the sacrifice of quality may have adverse effects on hospitals in the long run, and has currently deteriorated the relationship between doctors and patients. ${ }^{60}$ Therefore, we propose that sample hospitals should strictly supervise or even reduce hospital beds to coordinate the proportion among physicians, nurses and beds, which will help to guarantee the quality of care and benefit the efficiency eventually.

\section{Limitations}

This study has several limitations. First, the sample county hospitals were selected from Henan province, in central China, while hospitals located in the eastern and western areas were excluded. Second, as with many previous studies, we were temporarily unable to capture the quality of output. In addition, bias adjustments of efficiency and productivity scores were not carried out due to limitation of Coelli's basic DEA approach. In future research, a bootstrap DEA can be employed for more exact results. However, despite its limitations, this study can be considered as a useful preliminary study towards exploring the efficiency, productivity and impact factors in Chinese county hospitals during the period of healthcare reform.

\section{CONCLUSIONS}

This study provided an empirical picture of the technical efficiency and productivity of county hospitals in healthcare reform. Furthermore, environmental and institutional factors influencing hospital TE were also analysed.

The results indicated a considerable space for technical efficiency improvement in Henan county hospitals, since the average $\mathrm{TE}_{\mathrm{CRS}}$ was, respectively, 0.697, 0.748 and 0.790 for 2010, 2011 and 2012. To operate efficiently, there would be potential for significant input savings in inefficient hospitals. The results of the Malmquist index showed that sample county hospitals experienced a productivity progress of $7.8 \%$, which mainly resulted from the substantial improvement in TC. However, the results implied it might not have created any improvement in hospital governance or management over the period, owing to the deterioration in pure TEC.

The result of Tobit analysis indicated that government subsidy, hospital size with above 618 beds and ALoS were negatively associated with TE; while OCCU, ROBTN and RONTP were significantly positive with TE. So we proposed that county hospitals in Henan should strictly supervise or reduce hospital bed scale; shorten the average length of stay; and coordinate the proportion of physicians, nurses and beds, all of which would benefit the TE.

Acknowledgements The authors thank the Health and Family Planning Commission of Henan province, China, for their willingness to provide the data. Ashleigh Oguagha, an American student and native English speaker studying in the department, helped to further refine the revised manuscript to fulfil the high standards required for publication.

Contributors $\mathrm{ZC}, \mathrm{HT}$ and $\mathrm{HL}$ contributed to the conception and design of the project. ZC and $\mathrm{HL}$ contributed to the analysis and interpretation of the data. $\mathrm{QS}, \mathrm{XL}$ and $\mathrm{RZ}$ contributed to the data acquisition and provided statistical analysis support. ZC and MC drafted the article. All the authors supplied critical revisions to the manuscript and gave final approval of the version to be published.

Funding This work was supported by the National Natural Science Foundation of China (grant number 71173081).

Competing interests None declared.

Provenance and peer review Not commissioned; externally peer reviewed.

Data sharing statement No additional data are available.

Open Access This is an Open Access article distributed in accordance with the terms of the Creative Commons Attribution (CC BY 4.0) license, which permits others to distribute, remix, adapt and build upon this work, for commercial use, provided the original work is properly cited. See: http:// creativecommons.org/licenses/by/4.0/

\section{REFERENCES}

1. Yip W, Hsiao W, Meng QY, et al. Realignment of incentives for health-care providers in China. Lancet 2010;375:1120-30.

2. The National Health and Family Planning Commission NHFPC, PRC. The Ministry of Health is Positively Improve the Comprehensive Reform of County Hospitals. 2011. http://www.nhfpc. gov.cn/tigs/s3582/201106/dd75baa51fb844dc9df4f679a13f57b1. shtml (accessed 21 Jun 2014).

3. Li XM. Exploration on pathways of county hospital reform under the new situation. Prod Res 2012;11:126-7.

4. Fang $P Q$, Min R, Zou XX. Key points and pathway of county public hospital reform in China. Chin Hosp Manage 2014;34:4-8.

5. Wang HL, Xu TD, Xu J. Factors contributing to high costs and inequality in china's health care system. JAMA 2007;298:1928-30.

6. Wagstaff A, Yip W, Lindelow M, et al. China's health system and its reform: a review of recent studies. Health Econ 2009;182:S7-23.

7. Li L. The challenges of healthcare reforms in China. Public Health 2011;125:6-8.

8. Mccollum R, Chen L, Tang C, et al. Experiences with primary healthcare in Fuzhou, Urban China, in the context of health sector reform: a mixed methods study. Int J Health Plann Manage 2014;29: E107-26.

9. Yip W, Hsiao W. China's health care reform: a tentative assessment. China Econ Rev 2009;20:613-19.

10. Yip W, Hsiao W. Harnessing the privatisation of china's fragmented health-care delivery. Lancet 2014;384:805-18.

11. National Bureau Of Statistics Of China. China statistical yearbook. Beijing: China Statistics Press, 2014.

12. Hollingsworth B, Dawson PJ, Maniadakis N. Efficiency measurement of health care: a review of non-parametric methods and applications. Health Care Manag Sci 1999;2:161-72.

13. Barnum DT, Shields KL, Walton SM, et al. Improving the efficiency of distributive and clinical services in hospital pharmacy. J Med Syst 2011;35:59-70.

14. Dimas G, Goula A, Soulis S. Productive performance and its components in Greek public hospitals. Oper Res Int J 2012;12:15-27.

15. Zere E, Mcintyre D, Addison T. Technical efficiency and productivity of public sector hospitals in three South African provinces. S Afr J Econ 2001;69:336-58.

16. Tlotlego N, Nonvignon J, Sambo LG, et al. Assessment of productivity of hospitals in Botswana: a DEA application. Int Arch Med 2010;3:27.

17. $\mathrm{Ng}$ YC. The productive efficiency of Chinese hospitals. China Econ Rev 2011;22:428-39. 
18. Li H, Dong SP, Liu TF. Relative efficiency and productivity: a preliminary exploration of public hospitals in Beijing, China. BMC Health Serv Res 2014;14:158.

19. Henan Provincial Department of Finance, PRC. Research on the status of financial support in the reform of medical and health system in Henan province. 2014. http://www.hncz.gov.cn/sitegroup/ root/html/ff80808138b8ee81013b8d1502ed64b7/

20140529184854728.html (accessed 21 Apr 2015).

20. The Government of Henan Province, PRC. Total beds in secondary hospital of Henan province has reached up to 228,000. 2015. http:// www.henan.gov.cn/jrhn/system/2015/03/16/010535563.shtml (accessed 20 Apr 2015)

21. Worthington AC. Frontier efficiency measurement in health care: a review of empirical techniques and selected applications. Med Care Res Rev 2004;61:135-70.

22. Hollingsworth $B$. The measurement of efficiency and productivity of health care delivery. Health Econ 2008;17:1107-28.

23. Ozcan YA, Luke RD, Haksever C. Ownership and organizational performance: a comparison of technical efficiency across hospital types. Med Care 1992;30:781-94.

24. Magnussen J. Efficiency measurement and the operationalization of hospital production. Health Serv Res 1996;31:21-37.

25. Simar L, Wilson PW. Estimation and inference in two-stage, semi-parametric models of production processes. J Econometrics 2007;136:31-64.

26. Varabyova Y, Schreyogg J. International comparisons of the technical efficiency of the hospital sector: panel data analysis of OECD countries using parametric and non-parametric approaches. Health Policy 2013;112:70-9.

27. Charnes A, Cooper WW, Rhodes E. Measuring efficiency of decision making units. Eur J Oper Res 1978;3:429-44.

28. Banker RD, Charnes A, Cooper W. Some models for estimating technical and scale inefficiencies in data envelopment analysis. Manag Sci 1984;30:1078-92.

29. Cooper W, Seiford L, Tone K. Data envelopment analysis a comprehensive text with models, applications, references and Dea-Solver software. New York: Springer, 2007.

30. Färe R, Grosskopf S, Norris M, et al. Productivity growth, technical progress, and efficiency change in industrialized countries. Am Econ Rev 1994;84:66-83.

31. Lovell C. The decomposition of Malmquist productivity indexes $J$ Prod Anal 2003;20:437-58.

32. Nayar P, Ozcan YA, Yu F, et al. Benchmarking urban acute care hospitals: efficiency and quality perspectives. Health Care Manag Rev 2013;38:137-45.

33. Jehu-Appiah C, Sekidde S, Adjuik M, et al. Ownership and technical efficiency of hospitals: evidence from Ghana using data envelopment analysis. Cost Eff Resour Alloc 2014;12:9.

34. Chilingerian JA. Evaluating physician efficiency in hospitals: a multivariate analysis of best practices. Eur J Oper Res 1995;80: $548-74$

35. Asbu EZ. Hospital efficiency in Sub-Saharan Africa: evidence from South Africa. Working Paper No. 187. Helsinki: The United National University World Institute for Development Economic Research, 2000.

36. Ozcan YA, Luke RD. A national study of the efficiency of hospitals in urban markets. Health Serv Res 1993;27:719-39.

37. Sherman HD. Hospital efficiency measurement and evaluation: empirical test of a new technique. Med Care 1984;22:922-38.

38. Kirigia JM, Asbu EZ. Technical and scale efficiency of public community hospitals in Eritrea: an exploratory study. Health Econ Rev 2013;3:6.

39. Gok MS, Sezen B. Analyzing the ambiguous relationship between efficiency, quality and patient satisfaction in healthcare services: the case of public hospitals in Turkey. Health Policy 2013;111:290-300.
40. Coelli T. A guide to Deap version 2.1: a data envelopment analysis computer programme. Cepa Working Paper No. 8/96. Armidale: University Of New England, 1996.

41. Afonso A, Aubyn MS. Assessing health efficiency across countries with a two-step and bootstrap analysis. Appl Econ Lett 2011;18:1427-30.

42. Rahman MA, Capitman JA. Factors affecting profit efficiency of private hospitals in Bangladesh: are urban hospitals more profit-efficient? J Health Manag 2012;14:83-96.

43. Rosko MD, Chilingerian JA, Zinn JS, et al. The effects of ownership, operating environment, and strategic choices on nursing home efficiency. Med Care 1995;10:1001-21.

44. Statacorp. Stata 10 data analysis and statistical software. Texas: Stata Corp, 2010.

45. Ao JG, Wan YP, Yu WZ. The operation efficiency of county hospitals in Jiangxi province based on dea model. Chin J Health Stat 2014;31:1007-9.

46. Xu YC, Wang RH, Fu GJ. An analysis of technical efficiency in county public hospitals: based on data envelopment analysis. Chongqing Med 2013;42:3939-44.

47. The Central People's Government, PRC. To further encourage and guide the social capital in establishing medical institutions. 2010 http://www.gov.cn/zwgk/2010-2/03/content_1759091.htm (accessed 20 Oct 2014).

48. The Central People's Government, PRC. The outline of the National Health Service System (2015-2020). 2015. http://www.gov.cn/ zhengce/content/2015-3/30/content_9560.htm (accessed 20 Apr 2015)

49. Wang Y, Sun Q, Wang HP, et al. Dynamic efficiency of county hospitals in Shandong province: a data envelopment analysis-Malmquist index approach. Chin Public Health 2015;31:620-3.

50. Ouellette $P$, Vierstraete $V$. Technological change and efficiency in the presence of quasi-fixed inputs: a DEA application to the hospital sector. Eur J Oper Res 2004;154:755-63.

51. Gannon B. Total factor productivity growth of hospitals in Ireland: a nonparametric approach. Appl Econ Lett 2008;15:131-5.

52. Kirigia JM, Emrouznejad A, Cassoma B, et al. A performance assessment method for hospitals: the case of municipal hospitals in Angola. J Med Syst 2008;32:509-19.

53. Lobo MSC, Ozcan YA, Silva ACM, et al. Financing reform and productivity change in Brazilian teaching hospitals: Malmquist approach. Cent Eur J Oper Res 2010;18:141-52.

54. Pang HM, Wang XJ. Evaluating efficiency of level III general hospitals in China based on DEA Malmquist index. Chin Hosp Manage 2010;30:35-7.

55. Barber SL, Borowitz M, Bekedam H, et al. The hospital of the future in china: China's reform of public hospitals and trends from industrialized countries. Health Policy Plann 2014;29:367-78.

56. Tan ZJ, Lin JY, Lei HC, et al. Study on optimal scaling of secondary public general hospitals in Beijing. Chin J Hosp Admin 2014;30:385-95.

57. Dong SP, Xiao QQ, Liang MH. Study on economical efficiency of scale in county general hospitals based on data envelopment analysis. Chin Health Econ 2011;30:67-70.

58. Vitaliano DF. On the estimation of hospital cost functions. $J$ Health Econ 1987;6:305-18.

59. Centers for Disease Control and Prevention, USA. Number of hospital discharges, number of days of hospital stay, and average length of stay for discharges with diabetes as first-listed diagnosis, by age, United States, 1988-2009. http://www.cdc.gov/diabetes/ statistics/dmfirst/byagetable1_2.htm (accessed 20 Sep 2014).

60. World Health Organization $(\overline{\mathrm{W}} \mathrm{HO})$. Statistical information system 2010. http://www.who.int/whosis/whostat/2010/en/index.html (accessed 19 Mar 2014). 